\title{
Computational analysis of micro wind turbine with bamboo blades for domestic applications
}

\begin{abstract}
A domestic purpose micro wind turbine realised using bamboo blade is tested for the power generation at an interval of two years and compared the performance. A CFD analysis of turbine with five blade system is carried out for an average wind velocity of $2.5 \mathrm{~m} / \mathrm{s}$ and structural integrity of the bamboo blade unit based on the pressure distribution is assessed. For the input wind velocity, a stream lined out flow of $5.9 \mathrm{~m} / \mathrm{s}$ is found when wind turbine rotates at 300 rpm and corresponding pressure distribution is found to be maximum at the expected location of blade tip as $129 \mathrm{~Pa}$. The static analysis shows a good margin. For $2.5 \mathrm{~m} / \mathrm{s}$, a wind turbine generates an average value of $3.8 \mathrm{~V}$ with $0.25 \mathrm{~A}$ (based on $15 \Omega / 10 \mathrm{~W}$ load). The wind turbine has produced nearly the same power even after a period of two years.
\end{abstract}

\section{Introduction}

$\mathrm{E}$ nergy is becoming an imperious aspect of resource on earth. The power generation problem is one of the important aspects of the world in the field of energy sources. Power can also be obtained from renewable resources, which include hydropower plants, solar power plants, and thermal power plants and most importantly wind power plants. The current energy trend is increasing day by day.To cater efficient use of power and also looking forward to different options to meet the present power demand, varying electrical power consumption rates are thought of. Wind power is one of the cleanest forms of renewable energy resources. Wind farms in Ramakkalmeduin 2008 for 100MW and in Kanjikodein 2015 of 50 MW capacities are one of the wind farms installed in Kerala [1-2]. These units produce a generated output of $10.5 \mathrm{MW}$ with an average wind speed of around $6.8 \mathrm{~m} / \mathrm{s}$ and $7 \mathrm{~m} / \mathrm{s}$. The size of such wind turbine blade is of $35 \mathrm{~m}$ length (116 feet), a base width of $0.75 \mathrm{~m}$.

Fixed pitch wind turbines are used in power generation systems for generating power varying from small to middle power. Presently, high and medium power systems use the variable-pitch wind turbines, while fixed pitch turbines find

Messrs. J. Suraj Sayed, Post Graduate Student, R. Ramesh Kumar, Professor, Dept. Mechanical Engineering, Govt. Engineering College Barton Hill, Thiruvananthauram, Kerala, 695038 and Mr. P. V. Sreeram, Project Engineer, Energy Management Centre, Thiruvananthapuram, Kerala, 695017. E-mail: rameshkumar9446@gmail.com its usage limited to various low-power applications. In large wind turbines, the power extracted is controlled by means of the blade pitch angle and the turbine speed. When the power range of the turbines is smaller, the power is controlled by either turbines that control the speed and not the pitch angle or turbines that change the pitch angle and not speed. The mechanical power characteristic of a fixed-pitch turbine is expressed as a function of wind speed. Using micro wind turbine maximum value of the power variation is obtained for each wind speed [3].

Subramanian in 2019 carried out CFD analysis to check the aerodynamic design performance on a six bladed wind turbine system using ANSYS-FLUENT to predict the performance of blades at low wind velocities [4]. He has compiled work carried out by various authors [5-11]. Karna et al. in 2014 made a brief study on CFD analysis of an air-foil and they provided information on relationship of drag, life, forces, and its impact on airfoils [5]. From the study, it is clear to find drag and lift forces using CFD methodology. The analysis of the two-dimensional subsonic flow over a NACA 0012 air-foil at various angles of attack and operating at a Reynolds number of $3 \times \mathrm{E}+06$ is made and the CFD simulation results showed a close agreement with the experiments, thus suggesting a reliable alternative to experimental method in determining drag and lift. He also explained about the wind tunnel testing method to determine air-foil lift and drag forces where the process is quite laborious and costly more than CFD techniques. Thus, validation of the research work was done through analytical method than validation by experimental testing. Optimizing wind turbine blade design for low wind speed areas on improvement of blade aerodynamics was studied by Amano et al. in 2013 [6]. Kymarkevadiyain 2013 conducted a study on CFD analysis of NACA 4412 airfoil and concluded that at $0^{\circ}$ pressure coefficient of upper surface indicate negative pressure [7]. When increase in the angle of attack results in decrease in the pressure coefficient on upper surface and increase on lower surface it becomes maximum at $12^{\circ}$. Eleni et al. in 2012 carried out analysis of the two dimensional subsonic flow over a National Advisory Committee for Aeronautics (NACA) 0012 air-foil at various angles of attack and operating at a Reynolds number of $3 \times 10^{6}[8]$. The flow was obtained by solving the steady-state 
governing equations of continuity and momentum conservation combined with one of three turbulence models (Spalart-Allmaras, realizable and shear stress transport [SST]). They validated models through the comparison of the predictions and the free field experimental measurements for the selected air-foil. Overview on low power-low cost horizontal axis wind turbine for 350 watt application was proposed by Pedro et al [9] and implemented a low power horizontal axis wind turbine where the axis of rotation is parallel to the ground. Rotor, blades, supporting hub, and drive train were designed using computational software. Implemented wind turbine was tested and experimental results were obtained for $3.5 \mathrm{~m} / \mathrm{s}$ to $9 \mathrm{~m} / \mathrm{s}$ wind speed. In 2009 , Thumthae et al. recommended the importance of optimal angle of attack for untwisted blade in wind turbine [10]. Hence the numerical simulation of horizontal axis wind turbines with untwisted blade is performed to determine the optimal angle of attack that produces the highest power output. McKittrick et al. in 2001 presented a detailed report on analyzing the CFD techniques and it is found CFD methodology can effectively predict the load characteristics of wind turbines [11]. It is concluded that pressure distributions obtained from CFD calculations can be employed as load conditions. Reported study highlighted two areas in CFD which require for investigation transition point prediction and turbulence modelling. The laminar to turbulent transition point is modelled in order to get accurate results for the drag coefficient at various Reynolds numbers.

Holmes et al. in 2009 described bamboo has good mechanical performance [12]. It has greater fracture toughness, relatively specific strength and modulus than woods. In addition, the processing cost is not high and bamboo grows quickly. They concluded that bamboo would be a good material for blade building. However, for very large bamboo has to be incorporated into composites for wind turbine blade applications because single bamboo stalks are not big enough for a blade.

Sreeram et al. in 2017 realised a micro power generating wind turbine and compared the performance replacing five numbers of carbon-nylon composite blade with five numbers of compressed wood bamboo blades of 0.7 times less blade length and more suitable for domestic use [3]. Fig.1 shows the wind turbine with compressed wood bamboo blade. A $12 \mathrm{~V}$ $100 \mathrm{Ah}$ battery was used to regulate the power output to a connected load of $15 \Omega 10 \mathrm{~W}$. The prototype turbine with composite blade running at 267rpm at a wind speed of $2.5 \mathrm{~m} / \mathrm{s}$ produced $1.1 \mathrm{~W}$ output as against $0.95 \mathrm{~W}$ by the bamboo blade turbine at similar conditions. The cost of compressed bamboo wood blade wind turbine was around $25,000 /-$ when a single unit was fabricated in 2017. The enclosed volume of the domestic wind turbine is about $2.5 \times 1.5 \times 1 \mathrm{~m}$.

In the present study power generated using micro wind turbine of bamboo blades for domestic use is considered to compare the power generation for a period of an interval of

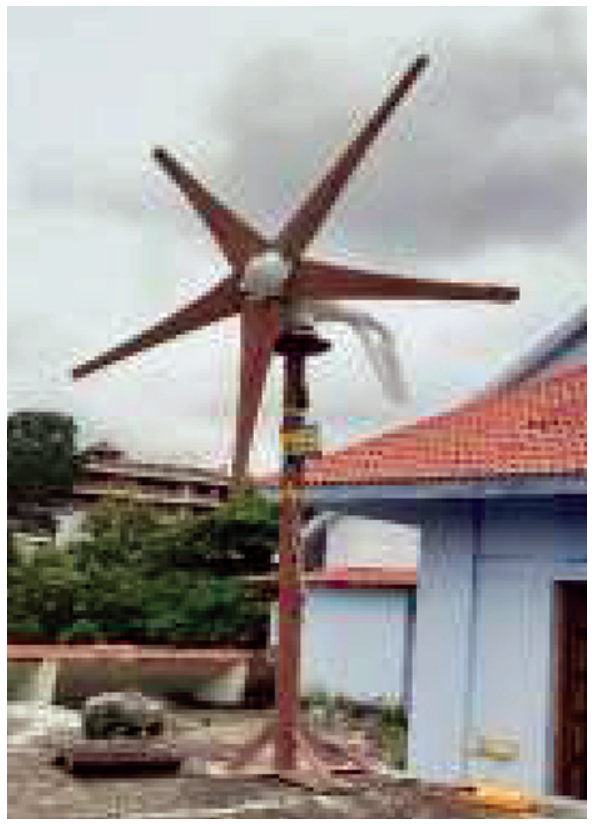

Fig.1 Small size wind turbine with five bamboo blades (micro)

two years and carry out CFD analysis for a wind velocity of $2.5 \mathrm{~m} / \mathrm{s}$ to determine the pressure distribution and velocity profile over the turbine with five bamboo blade assembly to assess the structural integrity as bamboo strips have poor transverse strength. To avoid additional composite fibre like glass or carbon reinforcement over the bamboo blade, the micro wind turbine is chosen.

\section{Rotor blade design}

A detailed design estimate was given in Ref.3 based on wellknown NACA 4412 air-foil. The purpose of the present study is to ensure design of wind turbine for domestic application by CFD analysis. Longer bamboo wind turbine blade length means greater power production. Blades capture the wind which forces the rotation of the rotor; a longer blade means more area for the wind to push against, which means greater force and rotational power.

In the realised configuration of the bamboo blade reported in Ref.3, the twist angle at blade root gradually varies and becomes zero at the tip while for the CFD analysis the twist angle is retained.

\subsection{Geometry of the Bamboo Blade}

Micro turbine category with rotor diameter of $1.2 \mathrm{~m}$

Length of the blade $0.53 \times 0.125 \times 0.002 \mathrm{~m}$ and blade

\subsection{Flexural strength of COMPRESSED BamboO wood}

Details of the specimen are as follows:

Specimen length along bamboo fibre direction, $\mathrm{L}=130 \mathrm{~mm}$ (between the two support points)

Width, $\mathrm{b}=25 \mathrm{~mm}$

Thickness, $\mathrm{t}=5 \mathrm{~mm}$ 
Three-point bend test is conducted on bamboo wood as shown in Fig.2. The maximum load obtained from the test is $529 \mathrm{~N}$ (average of three). The flexural strength is in the range of $125-165 \mathrm{MPa}$ while in the transverse direction it is obtained as $1 \mathrm{MPa}$.

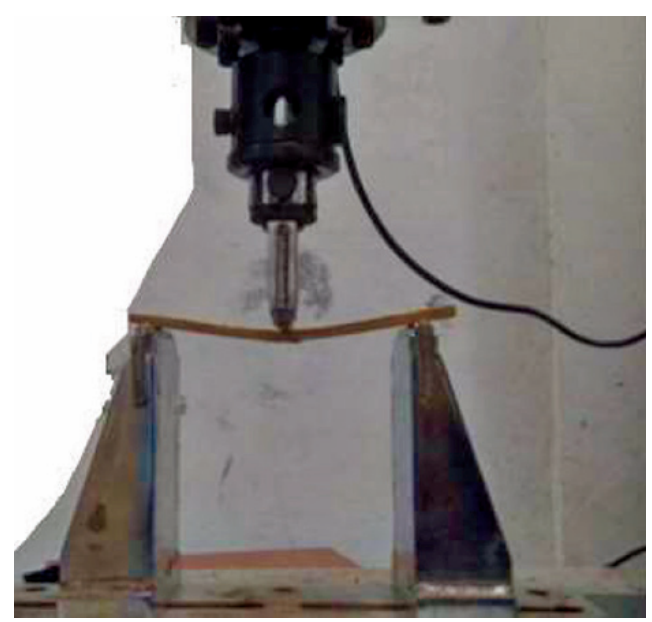

Fig.2 Flexural test on compressed bamboo wood
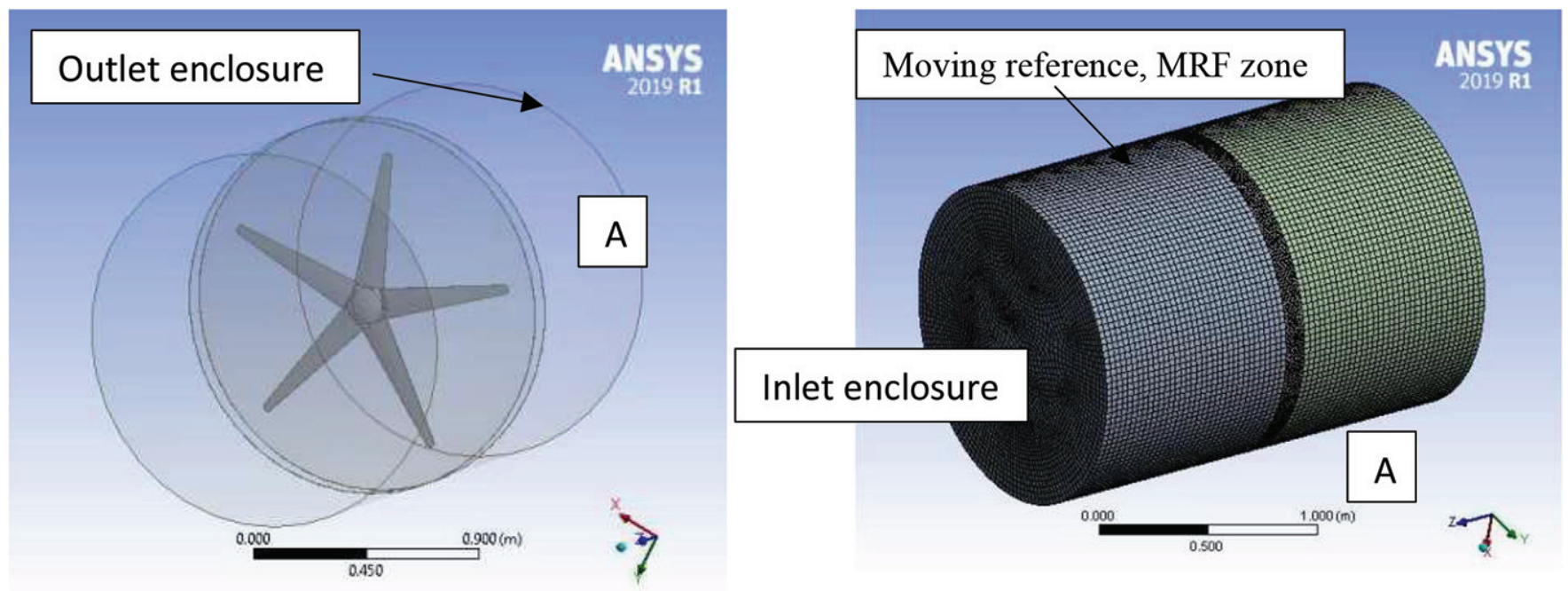

\section{CFD modelling}

In the present study, simulation of wind turbine is done by using ANSYS Workbench FLUENT R19.1. In ANSYS, design modeller is used for modelling the geometry and meshing is done in ANSYS AUTODYN. Then the mesh file is exported to a FLUENT solver and the post processing is done in ANSYS CFD-post.

The sequence of problem set-up is as follows:

\subsection{Geometric modelling}

Geometric modelling consists of drawing the geometry in suitable software for the analysis. The blade is modelled in CATIA software and assembled to form a five bladed wind turbine system. Then the model is imported into ANSYS software for analysis. In order to incorporate fluid flow interaction of the wind with the wind turbine a fluid domain known as moving reference zone (MRZ) is created surrounding the wind turbine as shown in Fig.3 using ANSYS design modeller. Then two enclosures namely inlet and outlet are created. The CFD analysis is carried out inside these

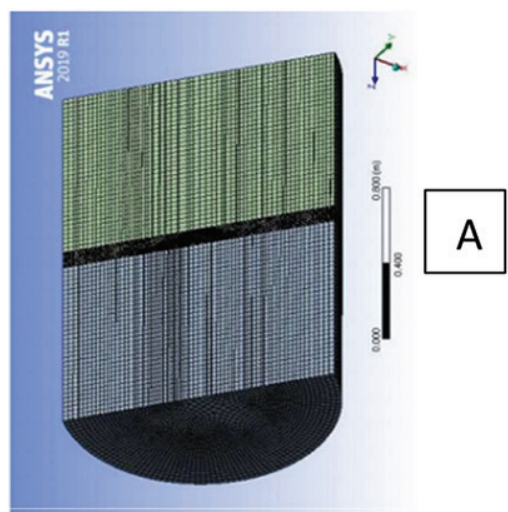

(a)

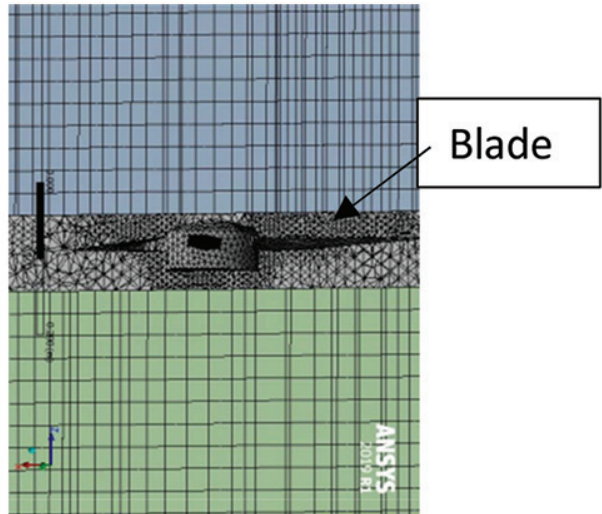

(b) 
enclosures where the inlet creates the medium of inlet wind, moving reference zone interacts with the wind turbine and the outlet represents the wind exiting from the MRZ.

\subsection{Procedure Followed For CFD MOdel FOR ANALysis}

The meshed configuration is then imported to FLUENT. A three-dimensional, double precision fluent solver with parallel processing is used for our problem. Pressure based and time function as steady state solver type is considered. A realizable $\mathrm{K}-\varepsilon$ model is chosen along with a standard wall function [11]. The cell zone condition of the MRF is given a frame motion and a counter clockwise rotation of (-) $300 \mathrm{rpm}$ is simulated. In the present analysis the turbine is rotated at (+) $300 \mathrm{rpm}$ and due to the inlet velocity; the pressure acting on the blades is obtained.

\subsubsection{Operating conditions}

(a) Pressure: $101325 \mathrm{~Pa}$.

(b) Density: $1.225 \mathrm{~kg} / \mathrm{m}^{3}$

\subsubsection{Solution method}

1. Pressure-velocity coupling: simple

2. Gradient: least squares cell based

3. Pressure: second order

4. Momentum: second order upwind

5. Turbulent kinetic energy: second order upwind

6. Turbulent dissipation rate: second order upwind

\subsubsection{Solution controls for under-relaxation factors}

\section{Density: 1,}

2. Body forces: 1

3. Momentum: 0.7

4. Turbulent kinetic energy: 0.8

5. Specific dissipation rate: 0.8

6. Turbulent viscosity: 1

It may be noted that 'hybrid initialization method' is invoked and 2000 iterations are given.

\section{Results and discussion}

Pressure distribution and velocity profile of wind force based on CFD analyses of wind turbine that consists of five bamboo blades that falls in the category of micro wind turbine with rotor diameter of $2 \mathrm{~m}$ and blade size of $0.6 \times 0.125 \mathrm{~m} \times 0.002 \mathrm{~m}$ are given in the Figs. 4 and 5 for an inlet velocity of $2.5 \mathrm{~m} / \mathrm{s}$. Variation in deformation and stress for the pressure distribution obtained are shown in Figs.6 and 7. Performance assessment of the wind turbine has been carried out for two years and the results are compared in Tables 1 and 2 .

\subsection{Pressure distribution over the Blade}

Fig.4 depicted the pressure variation on the bamboo blade when the wind turbine is subjected to an inlet velocity of 2.5 $\mathrm{m} / \mathrm{s}$. It is quite obvious from the pressure contour on the

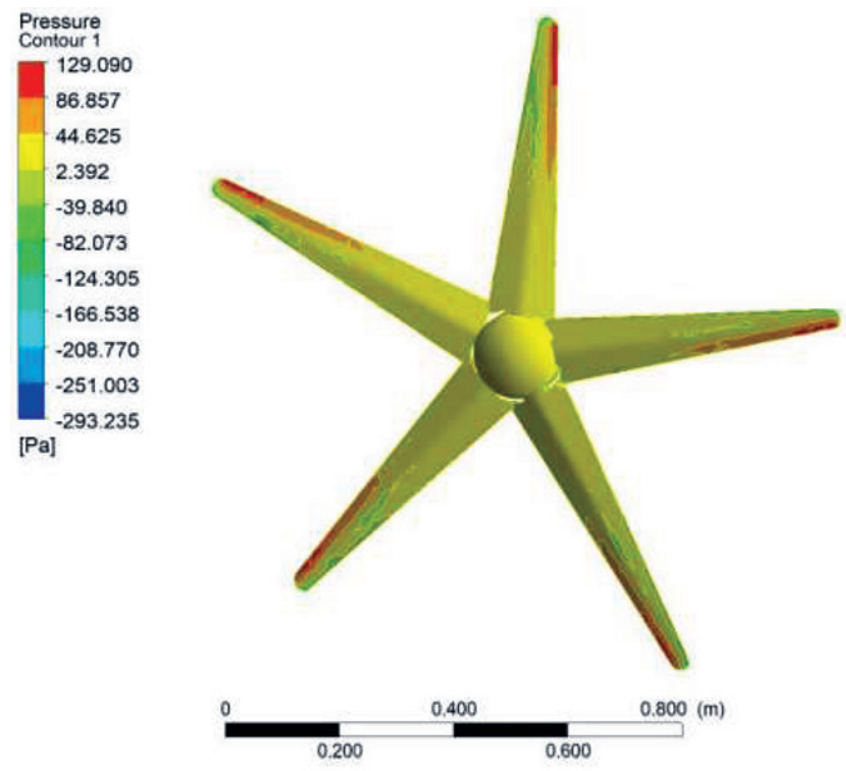

Fig.4 Pressure contour over the blade

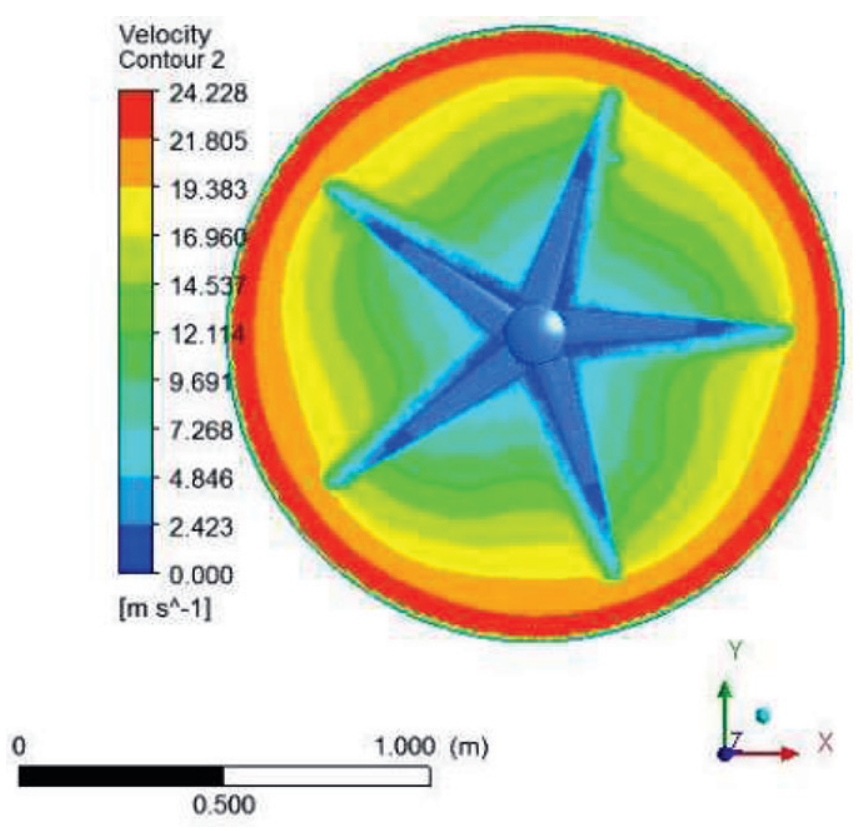

Fig.5 Velocity contour of over the blade

blade that the surface is subjected to a maximum pressure of $129 \mathrm{~Pa}$ at the blade tip over about $50 \%$ of the blade length. The velocity contour has indicated a maximum wind speed at the centre of the turbine blade and almost zero at the periphery (Fig.5).

\subsection{Static AnALYSis}

Corresponding to the pressure variation obtained for the turbine from CFD analysis, static analysis is carried out. The maximum deflection and stress are observed at the expected locations of the assembled turbine blade tip and root 


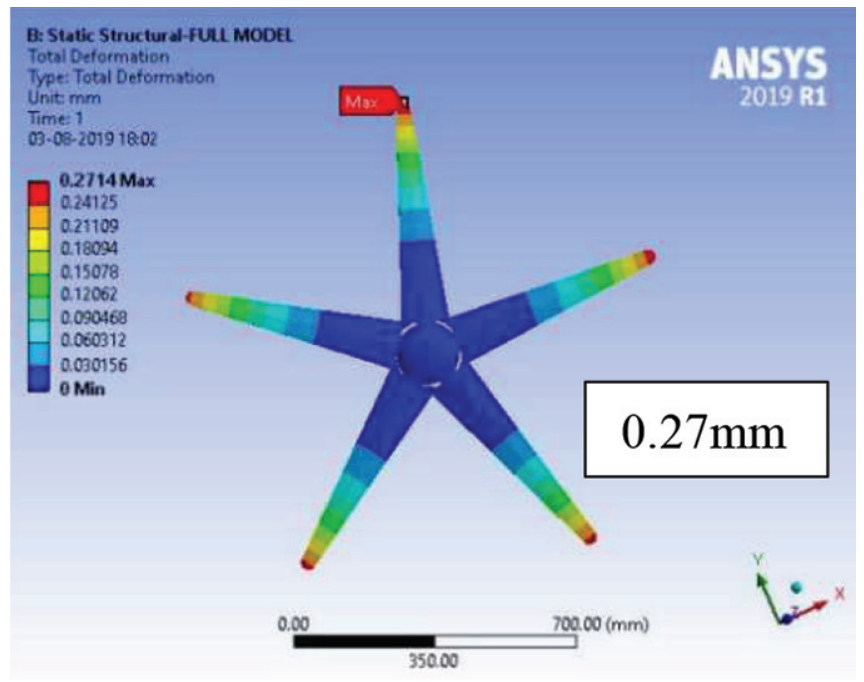

Fig.6 Deflection of blade (for 129Pa)

respectively (Figs.6 and 7). The maximum deflection of $0.27 \mathrm{~mm}$ is quite negligible and it subtends an angle only 1.5 minutes. It may be noted that the when compared the minimum flexural strength of $125 \mathrm{MPa}$ the expected fibre stress is $0.49 \mathrm{MPa}$ (Fig.7). It may also be noted that the transverse to bamboo fibre direction strength is $1 \mathrm{MPa}$ and the bamboo blade is still quite safe. Thus, it is concluded that the compressed bamboo blade is safe against the structural loads.

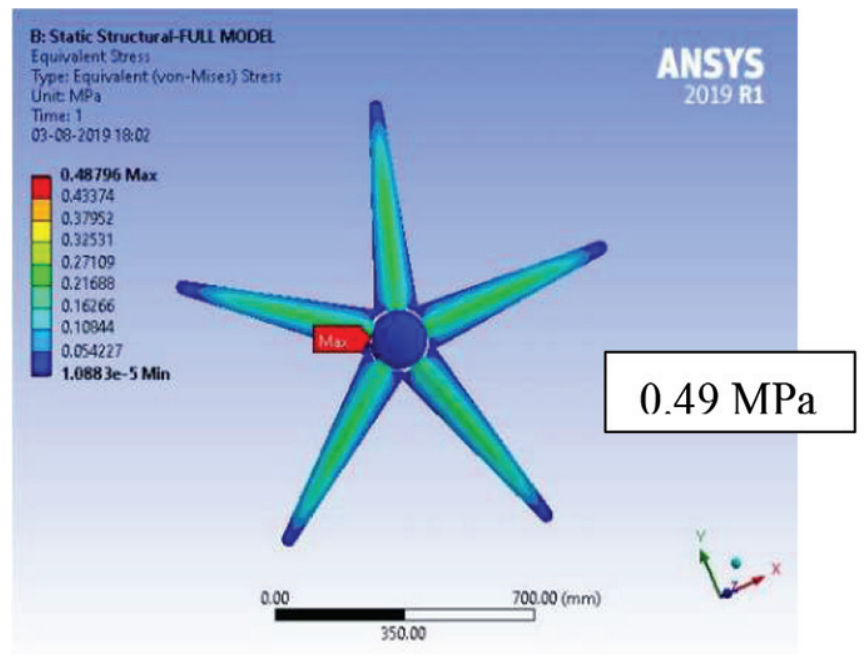

Fig.7 Stress distribution of blade

4.3 Power generated by Bamboo BLAde Wind tURBine DURING THE YEAR 2017 AND 2019

Experimental investigation was conducted to record the wind speed, time, voltage, current power and corresponding rpm during the July 2017 and August 2019 and given in Tables 1 and 2. It may be noted that the power generation is found to be similar as in the year 2017 as $3.8 \mathrm{~V}$ with $0.25 \mathrm{~A}$ based on $15 \mathrm{ohm} / 10 \mathrm{~W}$ load.

TABLE 1: Voltage AND CURRENT GENERATED BY DOMESTIC WIND TURBINE DURING JUNE 2017

\begin{tabular}{|c|c|c|c|c|c|}
\hline Speed $(\mathrm{m} / \mathrm{s})$ & Time $(\min )$ & Voltage (V) & Current (A) & Power (W) & $\mathrm{rpm}$ \\
\hline 2.0 & $12.20 \mathrm{PM}$ & 3.1 & 0.20 & 0.62 & 190 \\
\hline 2.0 & $12.25 \mathrm{PM}$ & 3.1 & 0.20 & 0.62 & 191 \\
\hline 2.3 & $12.30 \mathrm{PM}$ & 3.5 & 0.23 & 0.81 & 218 \\
\hline 2.9 & $12.35 \mathrm{PM}$ & 4.5 & 0.30 & 1.35 & 275 \\
\hline 2.5 & $12.40 \mathrm{PM}$ & 3.8 & 0.25 & 0.95 & 237 \\
\hline 2.6 & $12.45 \mathrm{PM}$ & 4.0 & 0.26 & 1.04 & 247 \\
\hline 2.5 & $11.30 \mathrm{PM}$ & 3.8 & 0.25 & 0.95 & 237 \\
\hline 2.8 & $11.45 \mathrm{PM}$ & 4.3 & 0.28 & 1.20 & 266 \\
\hline 3.0 & $11.50 \mathrm{PM}$ & 4.6 & 0.30 & 1.38 & 285 \\
\hline 4.8 & $12.00 \mathrm{PM}$ & 7.4 & 0.5 & 3.70 & 456 \\
\hline 4.0 & $12.15 \mathrm{PM}$ & 6.2 & 0.41 & 2.54 & 380 \\
\hline
\end{tabular}

Table 2: Voltage and CuRrent Generated by domestic Wind turbine during July-August 2019

\begin{tabular}{|c|c|c|c|c|c|}
\hline Speed $(\mathrm{m} / \mathrm{s})$ & Time (min) & Voltage (V) & Current (A) & Power (W) & $\mathrm{rpm}$ \\
\hline 2.5 & $12.00 \mathrm{PM}$ & 3.8 & 0.25 & 0.95 & 237 \\
\hline 3.3 & $12.05 \mathrm{PM}$ & 4.5 & 0.30 & 1.35 & 267 \\
\hline 3.5 & $12.10 \mathrm{PM}$ & 4.9 & 0.33 & 1.62 & 281 \\
\hline 4.2 & 12.15 PM & 6.8 & 0.45 & 3.06 & 340 \\
\hline 3.1 & $12.20 \mathrm{PM}$ & 4.0 & 0.27 & 1.08 & 254 \\
\hline 3.6 & $12.25 \mathrm{PM}$ & 5.3 & 0.35 & 1.86 & 290 \\
\hline 4.0 & $12.30 \mathrm{PM}$ & 6.2 & 0.41 & 2.54 & 323 \\
\hline 3.7 & $12.35 \mathrm{PM}$ & 5.7 & 0.38 & 2.17 & 297 \\
\hline
\end{tabular}




\section{Conclusion}

Wind turbine with bamboo blades (without any additional composite fibre reinforcing) has been tested for power generation suitable for domestic use for an interval period of two years. A good consistency in measured power out of $3.8 \mathrm{~V}$ with $0.25 \mathrm{~A}$ based on $15 \mathrm{~h} / 10 \mathrm{~W}$ load for a wind speed of 2.5 $\mathrm{m} / \mathrm{s}$ or $237 \mathrm{rpm}$ has been achieved. Present CFD analysis results for the similar five blade configuration has shown good structural integrity based on the pressure distribution over blade by comparing stresses with flexural strengths. The velocity contour has indicated a maximum wind speed at the centre of the turbine blade and almost zero at the periphery. The blade deflection under the pressure is only $0.27 \mathrm{~mm}$ over $600 \mathrm{~mm}$ blade length.

\section{References}

1. Wind farm in Ramakkalmedu,www.ramakkalmedu.com

2. Wind farm Wind farm in Kanjikode, www.ksebkanjikode.com

3. Sreeram, P. V, Hema, R, Kumar, R. R, (2017): 'Performance assessment of bamboo blade wind turbine as a green composite', International Conference on Circuits and Systems, pp 359-363, December, 20-21, Kerala, doi: 10.1109/ ICCS1.2017.8326021.

4. Subramanian, S S. (2019): 'CFD analysis of wind turbine blade for low wind speed', International Research Journal of Engineering and Technology (IRJET), vol. 6(3), pp-675-700.

5. Karna, S. P, Saumil, B. P, Utsav, B. P and Ahuja, A. (2014): 'CFD Analysis of an Airfoil', International Journal of Engineering Research, vol.3, pp. 154-158.

6. Amano R., Avdeev, I., Malloy, R. and Shams, M. Z.(2013): 'Power, structural and noise performance tests on different wind turbine rotor blade designs',
International Journal of Sustainable Energy, vol. 32(2), pp. 78-95, 2013.

7. Kymarkevadiya, M. (2013): 'CFD Analysis of Pressure Coefficient for NACA 4412', International Journal of Engineering Trends and Technology (IJETT), vol. 4(5), pp.2041-2043.

8. Eleni, D.C., Athanasios, T.I. andMargaris, P.(2012): 'Evaluation of the Turbulence models for the Simulation of the flow over a National Advisory Committee of Aeronautics(NACA) 0012 airfoil', Journal of Mechanical Engineering Research, vol. 4, pp. 100-111.

9. Pedro Bañuelos-Sánchez, Andrés Valle-Rodríguez, J. Mariano Fernández-Nava, Rubén Alejos-Palomares, and José Luis Vázquez-González (2011): 'Low power low cost horizontal axis wind turbine for 350 Watt application, $14^{\text {th }}$ International Conference on Electronics, Communications and Computers, 43 (6), 547-556, 1999.

10. Thumthae, C. and Chitsomboon, T. (2009): 'Optimal angle of attack for untwisted blade wind turbine, the numerical simulation of horizontal axis wind turbines (HAWTs) with untwisted blade, Renewable Energy, vol. 34(5),1279-1284, DOI: 10.1016/j.renene.2008.09.017.

11. McKittrick, L.R, Cairns, D.S, Mandell, J., Combs, D.C, Rabern, D.A and Van Luchene, R.D,(2002): 'Analysis of a Composite Blade Design for the AOC 15/50 Wind Turbine Using a Finte Element Method', Tech. Rep. SAND2001-1441, Sandia National Laboratories, 2001.

12. J.W. Holmes, P. Brøndsted (2009): Development of a Bamboo-Based Composite as a Sustainable Green Material for Wind Turbine Blades, March 1, Wind Engineering, SAGE publications https://doi.org/ 10.1260/030952409789141053

\section{Indian Journal of POWER \& RIVER VALLEY DEVELOPMENT}

\section{Special Issue on OTPC - A SUCCESS STORY}

For copies, please contact:

The Manager

BOOKS \& JOURNALS PVT. LTD.

62 Lenin Sarani, Kolkata 700013

E-mail: bnjournals@gmail.com 